\title{
Contribuições para a qualificação de professores de Física em formação inicial. Impactos sobre o uso de estratégias metacognitivas na resolução de problemas
}

\author{
Cleci T. Werner da Rosa* y Jesús Ángel Meneses V.**
}

Resumo. O presente texto apoia-se na importância de que, para os professores inovarem e ofertarem processos de aprendizagem mais significativos para seus alunos, é necessário que vivenciem isso durante sua formação. Desta forma o presente estudo descreve e analisa o modo como um grupo de futuros professores de Física percebem o uso da metacognição como estratégia de aprendizagem e de ensino. 0 estudo foi operacionalizado na forma de um curso de extensão universitária com o objetivo de abordar a temática metacognição e a forma como ela pode ser utilizada na resolução de problemas em Física. Para tanto, foram selecionados dez estudantes que durante 20 horas, em horário extraclasse, estudaram o tema e desenvolveram atividades voltadas a aprendizagem e discutiram formas de operacionalização como estratégia didática. Os resultados encontrados apontam que: o conteúdo abordado foi potencialmente significativo; que os alunos se mostraram motivados a aprender; que julgaram pertinente sua utilização, tanto no processo de aprendizagem das disciplinas do curso de graduação, como na sua atuação futura como professores; e, por fim, que valorizam ideias inovadoras como forma de buscar alternativas para qualificar o processo de ensino e aprendizagem na educação básica. Palavras-chave: futuros professores; metacognição; ensino de Física; conhecimento pedagógico.

CONTRIBUCIONES PARA LA CALIFICACIÓN DE PROFESORES DE FÍSICA EN FORMACIÓN INICIAL: IMPACTOS SOBRE EL USO DE ESTRATEGIAS METACOGNITIVAS EN LA RESOLUCIÓN DE PROBLEMAS

Resumen. El presente texto se basa en la importancia de que, los profesores para innovar y ofrecer procesos de aprendizaje más significativos para sus alumnos, necesitan experimentarlo durante su formación. De esta manera, el presente estudio describe y analiza el modo como un grupo de futuros profesores de Física perciben el uso de la metacognición como estrategia de aprendizaje y de enseñanza. El estudio se ha llevado a cabo en la forma de un curso de extensión universitaria con el objetivo de abordar la temática metacognición y la manera de utilizarla para hacer frente a los problemas en Física. Para ello, se han seleccionado diez estudiantes que, durante 20 horas en horario extraescolar, han estudiado el tema,

* Universidade de Passo Fundo (UPF), Brasil.

** Universidad de Burgos (UBU), España. 
desarrollado actividades dirigidas al aprendizaje, y discutieron formas de operación como una estrategia didáctica. Los resultados indican que: el contenido abordado fue potencialmente significativo; que los alumnos se mostraron motivados a aprender; que consideraron relevante su uso, tanto en el proceso de aprendizaje de las disciplinas en la licenciatura, como en su actuación futura docente; y, finalmente, que valoran ideas innovadoras como una manera de buscar alternativas para calificar el proceso de enseñanza y aprendizaje en la educación básica

Palabras clave: futuros profesores; metacognición; enseñanza de Física; conocimiento pedagógico.

CONTRIBUTIONS FOR THE QUALIFICATION OF PHYSIC'S TEACHERS IN PRESERVICE: IMPACTS ABOUT THE USE OF METACOGNITIVE STRATEGIES ON PROBLEM SOLVING

Abstract. The current text is based on the necessity for the teachers to experience a more meaningful learning during their formation, for them to innovate and offer that to their students. This way, the present study describes and analyses how a group of future teachers of Physics sense the use of metacognition as a strategy of learning and teaching. The study was held in the form of a university extension course with the goal of approaching the metacognition theme and how it can be used in the problem solving in Physics. For that, ten students were selected, and for 20 hours of class and some more extra hours, they studied and discussed the way of operationalization as a didact strategy. The results that were found point out the fact that the approached subject was very significant, the students showed themselves motivated to learn, the using of the strategy was judged very relevant, as much in the process of learning in the subjects of the university degree, as in the future performance as teachers, and to finish, they value the innovating ideas as a way of searching for new alternatives to qualify the teaching and learning process in basic education.

Keywords: future teachers; metacognition, physics teaching; pedagogical knowledge.

\section{INTRODUÇ̃̃OO}

A formação inicial de professores no Brasil configura entre as prioridades na educação desde o início do século XXI (Mello, 2000), pelo menos nos discursos oficiais. Várias iniciativas foram desenvolvidas na esfera política de modo a incentivar que os estudantes ao concluírem a educação básica optem por cursar uma graduação na área de licenciatura. Além disso, ações tem sido feitas como forma de qualificar a formação dos futuros professores, como é o caso do Programa Institucional de Bolsa de Iniciação à Docência (Pibid), implementado pelo governo federal em 2007, via Coordenação de Aperfeiçoamentos em Pessoal de Nível Superior (Capes). E o mais recente programa de Residência Pedagógica lançado pelo Ministério da Educação. 
No caso do Pibid, já em vigência no cenário nacional, sua finalidade é "fomentar a iniciação à docência, contribuindo para o aperfeiçoamento de formação de docentes em nível superior e para a melhoria da qualidade da educação básica pública brasileira" (Brasil, 2010). Como forma de incentivo, o programa financia bolsas a alunos de graduação que cursam licenciatura, professores das redes de educação básica que supervisionam as atividades desenvolvidas nas escolas e professores das Instituições de Ensino Superior (IES) que coordenam e organizam essas atividades desenvolvidas nas escolas. Dessa forma, tem-se um coletivo de pessoas envolvidas, nas quais os acadêmicos são organizados em grupo e divididos nas escolas que integram o programa, participando de atividades nas escolas e de reuniões semanais de preparação. Essas, por sua vez, são regidas pelo professor da IES - coordenador do subprojeto, contando com a participação dos acadêmicos e dos professores das escolas. Por meio desses três atores, o programa tem buscado aperfeiçoar a formação dos futuros professores de modo a proporcionar experiências inovadoras nas escolas e que possam contribuir para qualificar a formação inicial desses professores.

Entretanto, mesmo diante de alternativas buscadas pelo governo, um conjunto de entraves ainda se revelam presentes nos cursos de licenciatura, como mostrou Gatti (2014):

Há um acúmulo de impasses e problemas historicamente construídos e acumulados na formação de professores em nível superior no Brasil que precisa ser enfrentado. No foco das licenciaturas, esse enfrentamento não poderá ser feito apenas em nível de decretos e normas, o que também é importante, mas é processo que deve ser feito também no cotidiano da vida universitária. Para isso, é necessário poder superar conceitos arraigados e hábitos perpetuados secularmente e ter condições de inovar. Aqui, a criatividade das instituições, dos gestores e professores do ensino superior está sendo desafiada (p. 36).

No caso da formação de professores em Física, ações como as desenvolvidas pelo Pibid têm contribuído para atrair e manter os jovens no curso, mas ainda não dão conta de atender as demandas da área. Há um contingente de elementos contribuindo para isso, dentre eles o mais preocupante, como revelou o estudo de Ueno (2004), são as desistências que ocorrem ao longo do curso. A autora ao relatar os obstáculos enfrentados pelos estudantes da licenciatura em Física e as razões que tem levado as desistências, mostra dificuldades de diferentes naturezas, dentre as quais está a forma de pensamento característico e peculiar a Física. Nesse contexto, situa-se a resolução de problemas que exige uma forma de pensamento específico e que pode ser um entrave para alguns alunos na realização do curso. 
Por outro lado, como lembra Hinojosa e Sanmarti (2016), a resolução de problemas está entre os objetivos do ensino de Física e tem sido visto como uma maneira de familiarizar os alunos com a cultura da ciência. Ela é uma tarefa que privilegia a aprendizagem, em que se produz conhecimento e se associam os novos a diferentes situações, além de gerar um mecanismo em que o estudante combina informações teóricas com procedimentos, como cálculos aritméticos e algébricos, interpretação de gráficos, projeção de hipóteses e, também, com a motivação relacionada à atividade. Contudo, os problemas apresentados pelos livros didáticos especialmente os vinculados ao ensino superior, apresentam características de resolução que revelam uma estrutura de pensamento e de habilidades que muitas vezes os alunos não estão aptos ou não apresentam as estratégias adequadas para buscar possibilidades de resolução. Com isso, acabam por evadir do curso, ao invés de buscar alternativas que permitam qualificar sua aprendizagem.

Sobre esse tentame presente nos diferentes cursos de formação de professores de Física nas IES o presente texto se ocupa de discutir uma alternativa que busca favorecer a aprendizagem em Física, especificamente em termos da resolução de problemas. Trata-se da utilização da metacognição como estratégia de aprendizagem, cuja potencialidade tem sido revelada em vários estudos. Sobre isso Taasoobshirazi e Farley (2013) mencionam que a capacidade de resolver problemas está entre os objetivos do ensino de Física e inferem que a destreza neste tipo de atividade está relacionada a um conjunto de variáveis, tais como: a maneira como os problemas de Física são resolvidos, incluindo as estratégias reais de resolução de problemas usadas; a forma como os problemas são classificados o que sugere profundidade, amplitude e organização do conhecimento conceitual; as estratégias metacognitivas utilizadas; e se os problemas são representados de forma ilustrada na forma de um diagrama de corpo livre. Continuam os autores mencionando que essas variáveis contribuem para "o desenvolvimento da expertise em resolução de problemas de Física" (p. 53).

Frente a esses elementos, buscou-se desenvolver com um grupo de estudantes da licenciatura em Física de uma universidade comunitária localizada no interior do Rio Grande do Sul, estratégias metacognitivas voltadas a resolução de problemas de modo a contribuir para a melhoria no desempenho dos alunos nesse tipo de atividade. A partir de propostas encontradas na literatura envolvendo a resolução de problemas em Física por meio do uso de estratégias metacognitivas (Coleoni, e Buteler, 2009; Ryan et al.,2016; Hinojosa e Sanmarti, 2016; Moser, Zumbach e Deibl, 2017; Rosa e Ghiggi, 2017; Ghiggi, 2017, entre outras), foi desenvolvido um curso de 20 horas com os futuros professores de modo que eles tomassem conhecimento sobre os fundamentos da metacognição e sua associação com a resolução de problemas. 
Vale registrar que a metacognição não faz parte dos conhecimentos pedagógicos que integram a formação desses futuros professores na universidade investigada, portanto, representa algo novo, ao qual eles devem se apropriar de seus referenciais teóricos e da forma como pode ser utilizada na resolução de problemas. Esse contexto, aponta para a problemática referente a compreensão e aceitação dos futuros professores sobre o construto da metacognição e a forma como irão se apropriar e aplicar na resolução de problemas em Física.

Zohar e Barzilai (2013) apontam que as pesquisas em metacognição associado a Educação Científica têm aumentado significativamente nos últimos quinze anos, inferindo que a vinculação da metacognição com o ensino e a aprendizagem em Ciências tem encontrado respaldo na comunidade científica. Entretanto, as autoras se associam aos estudos de Georghiades (2004) e Thomas (2013) revelando que um dos aspectos carentes de investigação, encontra-se associado a discussão da metacognição nos cursos de formação inicial e continuada de professores. Sobre isso apontam ser um tema relevante para futuras investigações:

A proficiência dos professores nesta área [instrução baseada na metacognição] é crucial para concretizar este objetivo. Uma pesquisa futura seria necessária para estudar as condições em que os professores em formação inicial e professores que já atuam podem melhor aprender a lidar com as várias componentes metacognitivas para alcançar uma ampla gama de metas da Educação Científica e a melhor forma de fazer isso com os diferentes alunos (Zohar e Barzilai, 2013, p.154, tradução nossa)

Essa identificação ancora o estudo realizado na investigação apresentada neste texto que teve como objetivo principal analisar a forma como futuros professores de Física concebem a metacognição como possibilidade de qualificação da sua aprendizagem na resolução de problemas em Física. Tal análise se dá em duas esferas, enquanto estudantes de um curso de Física e, portanto, podendo usufruir desse recurso em sua própria aprendizagem e como futuros professores, no qual poderão avaliar a operacionalização como estratégia de ensino.

O intuito é que ao ter contato com a metacognição e os seus benefícios para a aprendizagem, os futuros professores possam refletir e modificar suas atitudes e crenças em relação aos objetivos do ensino, que tradicionalmente estão focados em aspectos conteudistas e pouco voltados ao desenvolvimento da compreensão de como se aprende ou a reflexão sobre seus conhecimentos e a autorregulação. 
Para alcançar tais objetivos, a pesquisa desenvolvida caracteriza-se como qualitativa e busca por meio de entrevistas semiestruturadas elucidar a percepção de um grupo de dez estudantes que cursam Física - Licenciatura e que atuam em projetos como o Pibid atendendo alunos do ensino médio, conforme relatado na continuidade.

\section{METACOGNIÇÃO NO CONTEXTO DA RESOLUÇÃO DE PROBLEMAS EM FÍSICA}

De acordo com o mencionado em estudo anterior (Rosa, 2011) e tomando-se por referências as discussões de Flavell (1976) a metacognição refere-se à identificação dos sujeitos sobre seus conhecimentos - tomada de consciência - e à regulação que eles fazem de seu sistema cognitivo - autorregulação. Tal entendimento é consensual entre autores que se dedicam aos estudos da metacognição em suas mais diferentes áreas, como a psicologia, educação, sociologia, etc... ou na vinculação da metacognição com diferentes campos do saber, como a Educação Científica. Entretanto, por mais que esse conceito mantenha um núcleo coeso sob o qual os pesquisadores têm discutido intervenções didáticas, distintas aproximações com outros conceitos tem sido realizadas, inferindo uma gama complexa de entendimento associadas a metacognição.

Mesmo diante dessas variações, Zohar e Barzilai (2013) inferem que o modelo clássico mencionado anteriormente tem sido o mais utilizado no campo da Educação Científica sendo a metacognição entendida a partir de duas componentes: conhecimento do conhecimento e controle executivo e autorregulador. A primeira é integralizada por três variáveis: pessoa, tarefa e estratégia. A variável pessoa está relacionada às convicções e aos mitos que o sujeito tem sobre sua própria cognição, as comparações que ele faz sobre si mesmos com os outros e aos conhecimentos relacionados ao que ele sabe sobre a cognição humana. A variável tarefa está ligada as características da tarefa em curso, tanto em termos do que ela é, como do que envolve. A variável estratégia relaciona-se a capacidade do sujeito em reconhecer que para cada tipo de objetivo, há estratégias disponíveis e de saber como usálas. (Flavell e Wellman, 1977). A segunda componente não foi detalhada por Flavell, mas por Brown (1978), ao inferir que a autorregulação e o controle executivo estariam vinculadas a três elementos: planificação, monitoramento e avaliação. 0 primeiro representa o planejamento das ações para a realização de uma tarefa de acordo com especificidades, como características e grau de exigência, em relação ao objetivo pretendido. A monitoração relaciona-se à capacidade do sujeito em verificar e controlar sua ação a fim de alcançar seus objetivos, englobando as intervenções que ele realiza por meio de suas 
estratégias. A avaliação, por sua vez, é entendida como a capacidade do sujeito de analisar a coerência do resultado obtido com o objetivo, revisando as estratégias que realizaram, quais conhecimentos são resultados da tarefa e também quais os possíveis erros que podem ter acontecido.

Entretanto, como mencionado há diferentes intepretações e associações relacionadas a metacognição, contudo considera-se o especificado como referência para o presente estudo, a exemplo do apresentado por Rosa (2011). Tal interpretação também tem sido utilizada para subsidiar estudos que mostram a diferença entre os alunos que são considerados com expertise na resolução de problemas em Física e que acabam tendo bons rendimentos acadêmicos, dos alunos que apresentam dificuldades neste tipo de atividade (novatos). Chi, Glaser e Rees (1982), Reif e Larkin (1991), Malone (2008), Taasoobshirazi e Farley (2013), entre outros, mostram que alunos que recorrem ao pensamento metacognitivo, mesmo sem se dar conta de que estão fazendo isso, apresentam melhor compreensão e resultados mais satisfatórios em Física que os que não o fazem.

Uma vez constatado essa relação, torna-se evidente que entre as tarefas didáticas do professor está a de utilizar essa forma de pensamento, especialmente porque apesar dela ser inerente ao ser humano, não é ativada espontaneamente por todos. Estudos como os desenvolvidos por Kistner et al. (2010) na Alemanha, mostraram que os ganhos mais significativos dos alunos em relação a metacognição ocorreram em situações nas quais os professores usam explicitamente tais estratégias e em acordo com os conteúdos. Questões apontadas por Monereo (2001) evidenciando a necessidade de os professores associarem as estratégias metacognitivas aos conteúdos de suas disciplinas curriculares, ressaltando que não se aprende a utilizar esse pensamento no vazio dos conteúdos, mas sim em consonância com eles.

A partir dessa identificação estudos tem mostrado a possibilidade de fazer essa associação em diversos campos do conhecimento e envolvendo diferentes ferramentas didáticas. Na resolução de problemas em Física, estudos como os mencionados na introdução deste texto, revelam possibilidades para sua utilização. Tais propostas evidenciam o uso de diferentes recursos e mostram que são inúmeras as possibilidades de tornar explicito a evocação do pensamento metacognitivo durante a resolução de problemas em Física. Dentre essas alternativas está a que utiliza trocas verbais entre estudantes como forma de ativar o pensamento metacognitivo (Ghiggi, 2017) e a orientação por guias do tipo prompts que são passos que possibilita retomar e refletir as ações em parceria com os colegas (Hinojosa e Sanmartí, 2016). E foi a parti dessas duas possibilidades que a pesquisa apresentada estruturou a sua ação e que passa a discutir na continuidade do texto. 


\section{ATIVIDADE DESENVOLVIDA}

A atividade desenvolvida refere-se a ações que envolvem a discussão dos conceitos de metacognição e a sua vinculação com a resolução de problemas em Física. Os problemas selecionados são típicos problemas de lápis e papel que tradicionalmente estão presentes nos livros didáticos de Física, tanto na educação básica como no ensino superior. A proposta didática apresentada aos alunos consistia em utilizar prompts orientativos (questionamentos metacognitivos) associado à discussão em pares (trocas verbais em duplas). A atividade foi desenvolvida durante 20 horas-aula, dividida em 4 encontros e envolveu dez alunos de um curso de Física.

O primeiro encontro iniciou pelo questionamento sobre metacognição e seus fundamentos teóricos, apoiando-se nas discussões de Rosa (2011). Nos encontros seguintes foi apresentado aos alunos a forma com eles poderiam se beneficiar deste construto na resolução de problemas.

Os prompts orientativos consistem em guias metacognitivos que são construídos pelos alunos de modo que possam orientar suas ações de pensamento durante a resolução dos problemas. Os questionamentos envolvem os seis elementos apontados no estudo de Rosa (2011) e que buscam uma reflexão de natureza metacognitiva. 0 quadro 1 a seguir ilustra exemplo de prompts orientativos utilizado pelos estudantes a partir da apresentação de um conjunto de possibilidades.

\section{QUADRO 1}

\section{Exemplo de prompt orientativo utilizado no estudo.}

\begin{tabular}{|c|}
\hline Questionamento Metacognitivo I \\
\hline $\begin{array}{l}\text { - Qual o sentimento em relação a tarefa proposta? } \\
\text { - Você julga ter conhecimento sobre o conteúdo abordado no problema? } \\
\text { - Quais os seus conhecimentos sobre a tarefa de resolver problemas em Física? } \\
\text { - No problema apresentado você identifica qual a melhor estratégia para resolvê-lo? Como } \\
\text { você se julga em relação a essa estratégia? }\end{array}$ \\
\hline Questionamento Metacognitivo II \\
\hline $\begin{array}{l}\text { - Qual a sua previsão/estimativa para o seu resultado do problema? } \\
\text { - Oomo você está planejando a forma de resolver este problema? } \\
\text { elementos necessários para isso? }\end{array}$ \\
\hline Questionamento Metacognitivo III \\
\hline $\begin{array}{l}\text { - A resposta encontrada era a esperada? Ela condiz com as previsões feitas? } \\
\text { - Qual o significado do resultado encontrado? } \\
\text { - Você julga que poderia ter resolvido o problema de outra forma? } \\
\text { - Você julga ter clareza da forma que resolveu o problema e dos caminhos escolhidos? }\end{array}$ \\
\hline
\end{tabular}

Fonte: elaboração própia, 2018. 
O segundo encontro foi destinado a construção desses prompts e a sua utilização de forma individual, para somente no terceiro e com os guias construídos por cada aluno pudesse contemplar a segunda parte da proposta: interação com os pares. No terceiro encontro, os alunos de posse de seus prompts receberam um conjunto de problemas selecionados aleatoriamente junto a um livro de Física Geral - Eletricidade e passaram a resolver tais problemas dentro da abordagem didática proposta neste estudo. O Quadro 2 a seguir exemplifica a sequência de etapas estabelecida na proposta e executada pelos alunos a partir do terceiro encontro.

\section{QUADRO 2}

\section{Etapas da proposta didática em estudo}

\begin{tabular}{|c|c|c|}
\hline Etapa & Atividade & Objetivo \\
\hline 1 & $\begin{array}{l}\text { Ler o problema individualmente e iden- } \\
\text { tificar/localizar a pergunta (incógnita } \\
\text { principal) }\end{array}$ & Ter contato com o objeto de estudo. \\
\hline 2 & $\begin{array}{l}\text { Responder o Questionamento Meta- } \\
\text { cognitivo I-pessoa, tarefa e estratégia, } \\
\text { de modo a estabelecer um diálogo com } \\
\text { seu colega. }\end{array}$ & $\begin{array}{l}\text { Refletir e discutir com o colega os sentimentos } \\
\text { em relação à atividade proposta e os conhe- } \\
\text { cimentos que julga possuir sobre o conteúdo, } \\
\text { tarefa de resolver problemas e sobre a estratégia } \\
\text { associada a esse tipo de problema. }\end{array}$ \\
\hline 3 & $\begin{array}{l}\text { Retomar a leitura do problema e de- } \\
\text { bater com o colega os conhecimentos } \\
\text { que vão necessitar para responder o } \\
\text { problema. }\end{array}$ & $\begin{array}{l}\text { Estabelecer uma conexão entre os conheci- } \\
\text { mentos já existentes e o problema proposto em } \\
\text { situação de diálogo entre pares. }\end{array}$ \\
\hline 4 & $\begin{array}{l}\text { Iniciar o processo de resolução do } \\
\text { problema, escolhendo a estratégia a } \\
\text { se utilizada. }\end{array}$ & Confrontar ideias e estabelecer acordos. \\
\hline 5 & $\begin{array}{l}\text { Responder o Questionamento Meta- } \\
\text { cognitivo II - planificação e monito- } \\
\text { ração, debatendo as ações realizadas } \\
\text { com seu colega. }\end{array}$ & $\begin{array}{l}\text { Planificar e monitorar a ação em desenvolvi- } \\
\text { mento. }\end{array}$ \\
\hline 6 & $\begin{array}{l}\text { Revisar o procedimento realizado e o } \\
\text { resultado encontrado. }\end{array}$ & $\begin{array}{l}\text { Verificar e corrigir possíveis equívocos de } \\
\text { cálculos. }\end{array}$ \\
\hline 7 & $\begin{array}{l}\text { Destacar e analisar a resposta encon- } \\
\text { trada confrontando com o identificado } \\
\text { na etapa } 1 .\end{array}$ & $\begin{array}{l}\text { Confrontar o resultado obtido frente ao identi- } \\
\text { ficado como pergunta do problema. }\end{array}$ \\
\hline 8 & $\begin{array}{l}\text { Responder o Questionamento Meta- } \\
\text { cognitivo III - avaliação, de modo a } \\
\text { discutir com o colega as escolhas e } \\
\text { os procedimentos realizados. }\end{array}$ & $\begin{array}{l}\text { Avaliar a ação desenvolvida, em termos do con- } \\
\text { hecimento adquirido, das escolhas realizadas e } \\
\text { do procedimento adotado. }\end{array}$ \\
\hline
\end{tabular}

Fonte: elaboração própia, 2018.

O quadro anterior ilustra os passos realizados durante a resolução de cada um dos problemas e serviram de referência para o terceiro, quarto e quinto encontro. 0 quadro 3 ilustra o apresentado anteriormente de forma esquemática e simplificada. 


\section{QUADRO 3}

\section{Esquema de aplicação da proposta didática.}

\begin{tabular}{|c|c|}
\hline Exemplo de problema & Etapas a serem realizadas \\
\hline \multirow{8}{*}{$\begin{array}{l}\text { Em um circuito elétrico existem } \\
\text { três } 3 \text { resistores. As intensidades } \\
\text { das correntes elétricas que passam } \\
\text { por eles correspondem aos valores: } \\
\mathrm{i} 1=7,5 \mathrm{~A} \text {, i2 }=2,5 \mathrm{~A} \text { e i3 }=10 \mathrm{~A} \text {. } \\
\text { São dadas também as resistências: } \\
\mathrm{R} 1=20 \text { ohm e } \mathrm{R} 3=45 \text { ohm. } \\
\text { Determine o valor da resistência } \\
\text { do resistor } \mathrm{R} 2 \text { e da tensão aplicada } \\
\text { ao circuito. }\end{array}$} & - Leitura individual e identificação da pergunta \\
\hline & - Questionário Metacognitivo I \\
\hline & - Discussão com o colega \\
\hline & - Resolução do problema \\
\hline & - Questionamento Metacognitivo II \\
\hline & - Revisão do realizado \\
\hline & - Confronto da resposta com a identificação da pergunta \\
\hline & - Questionamento Metacognitivo III \\
\hline
\end{tabular}

Fonte: elaboração própia, 2018.

O exemplo mencionado no Quadro 3 refere-se a um típico exercício de lápis e papel e constitui objeto de estudo nos cursos de formação de professores. Nesses exercícios os alunos muitas vezes apresentam dificuldades de interpretação da situação apresentada, bem como de sua solução. Essa, por sua vez, passa por aspectos como a identificação da pergunta, a recuperação na memória dos conhecimentos necessários para resolver o problema e, especialmente, a avaliação do resultado encontrado frente ao solicitado e do percurso realizado para isso. Desta forma, acredita-se que a proposta didática estruturada contribuirá para a melhoria da aprendizagem dos alunos, nos diferentes níveis de escolarização.

\section{ASPECTOS METODOLÓGICOS}

A pesquisa desenvolvida foi caracterizada como qualitativa que de acordo com Bogdan e Biklen (1994) apresenta como objetivo compreender e descrever significados. De acordo com os autores essa abordagem é a mais indicada quando a investigação envolve dados decorrentes da fala ou conversa com pessoas, que são de complexo tratamento estatístico. E, ainda, podese dizer que a pesquisa qualitativa se revela importante quando busca-se examinar detalhes para poder estabelecer uma compreensão mais profícua da realidade estudada. No caso desta pesquisa, essa foi a prerrogativa para escolher uma análise qualitativa, considerando, entre outros aspectos, que os resultados seriam discutidos a partir da fala dos sujeitos.

Os dados analisados no estudo foram produzidos a partir de entrevistas do tipo semiestruturada cuja principal característica, conforme Lüdke e André (1986), está na flexibilização e possibilidade de interlocução 
do entrevistador com o entrevistado. Além disso, o uso dessa ferramenta permite um diálogo mais próximo e com possibilidade de inferências e de novos questionamentos a partir da fala do entrevistado.

Como sujeitos da pesquisa, tem-se os dez estudantes de um curso em Física - Licenciatura e que integram o Pibid, portanto, tem vivência em sala de aula com estudantes do ensino médio, atendo o objetivo de discutir as contribuições tanto em termos de sua aprendizagem, como as potencialidades para o ensino. Os estudantes que se encontram em diferentes etapas do curso, participaram por livre adesão e se mostraram envolvidos com as atividades realizadas. As entrevistas foram gravadas em áudio e transcritas na integra. Para realização das entrevistas estruturou-se um conjunto de itens/ questões que foram submetidas a três especialistas em pesquisas qualitativas que avaliaram a sua pertinência em termos de produção de materiais para o estudo pretendido. Após o retorno dessas análises os itens da entrevista foram ajustados e considerados os questionamentos do estudo.

As entrevistas foram realizadas em um período posterior ao curso realizado (cerca de 60 dias), uma vez que os alunos deveriam aplicar em suas aprendizagens o modelo proposto e somente após discorrer sobre sua percepção em relação a proposta em estudo. Desta forma, os sujeitos foram entrevistados a partir do momento em que puderam utilizar nas disciplinas do curso de Física as estratégias discutidas, particularmente o proposto em termos da resolução de problemas. Ainda, as entrevistas continham indagações sobre a utilização dessas estratégias no exercício profissional futuro.

Os dados coletados foram lidos na integra e analisados a partir do inferido por Bardin (2004) em termos da Análise de Conteúdo. No seu entender essa técnica representa um conjunto de métodos de análise das comunicações que buscam obter procedimentos sistemáticos e descrição do conteúdo das mensagens, permitindo inferência de conhecimentos relativos às condições de produção/recepção dessas mensagens. De acordo com a autora a técnica é adequada quando se deseja analisar apenas o texto e não suas relações com as formas como ele foi produzido.

Seguindo o proposto por Bardin (2004), para a análise do material coletado foi necessário o cumprimento de etapas que possibilitam chegar às categorias: pré-análise, exploração do material e tratamento e interpretação dos dados. A partir dessas etapas procedeu-se a sua codificação em unidades de registro e, por fim, a categorização. Para classificar os elementos em categorias foi preciso identificar o que os dados decorrentes das falas dos sujeitos apresentavam em comum, o que possibilitou seu agrupamento - categorias. 


\section{DISCUSSÕES}

Os resultados apresentados foram categorizados seguindo o discutido anteriormente e associados aos elementos que se revelaram as unidades de registro. As falas extraídas da transcrição dos dados, cuja reflexão ocorreu a partir do referencial teórico discutido neste texto, estão indicadas por fragmentos, sendo os sujeitos identificados pelo uso da letra "E" seguida de uma numeração que inicia no "1" e acaba em "10". Em termos de gênero, o estudo envolve sete estudantes do sexo masculino e três do sexo feminino, conforme declarados pelos estudantes na parte inicial da entrevista. Entretanto, utiliza-se, ao longo do texto, o gênero masculino para identificar qualquer um dos entrevistados. Por fim, destaca-se que os fragmentos de fala utilizados a seguir foram corrigidas em termos dos vícios de linguagem, conforme indicado por Duarte (2004) ao ressaltar que as falas devem ser editadas de maneira a preservar sua essência, mas também retirar elementos (cacoetes, falas incompletas...) que deixam a leitura menos fluida e mais cansativa.

\subsection{Conhecimento sobre metacognição}

Esta categoria emergiu da fala dos estudantes que fizeram questão de mencionar que não apresentavam conhecimentos sobre metacognição, exceto dois que julgaram ter algum conhecimento sobre o assunto. Esses dois alunos relataram a realização de curso na universidade vinculado ao tema e um deles mencionou ser integrante de projeto de pesquisa na área. Os demais revelaram que o termo representava algo novo apesar de saber da existência de estudos sobre metacognição no curso de Física que realizam, mas que não tinham ideia do que se tratava.

A fala do estudante $\mathrm{E} 4$ expressa o sentimento dos alunos em relação a temática metacognição:

Eu não sabia o que era, mas ouvi falar que a professora ... pesquisa isso. Até fiquei curioso, mas achei que era algo difícil e complexo, alguma coisa que envolvia muito conhecimento em educação, coisa que eu não tinha, por isso não me interessei em ler nada. Mas agora vi que é simples e fácil de entender, algo que posso praticar e aprender melhor. Sabe, as vezes temos medo de aprender algo, depois percebemos que é mais fácil do que imaginamos e aí até gostamos de estudar. Assim foi com a Física, que no primeiro ano no colégio, eu tinha medo porque a professora assustava, mas depois tive uma professora ótima, que me fez entender e gostar da Física, por isso estou aqui hoje ... quem sabe no mestrado eu pesquise metacognição! 
O expresso por E4 ilustra que o grupo havia ouvido menção ao termo "metacognição", entretanto, não apresentava conhecimento sobre o assunto. Outra característica importante representada na fala de E4 e igualmente expressa por E1, E3, E5, E6, E7, E8, E9, vincula-se ao fato de que aprender algo novo inicia por um sentimento de capacidade de compreensão; de que aquilo que está sendo apresentado é algo potencialmente significativo para eles; e, que há prazer, satisfação na aprendizagem. Esse sentimento é representado pelo domínio afetivo e conforme Efklides (2006) faz parte das experiências metacognitivas. Portanto, iniciar por algo que se revela em sintonia com os alunos, mostrando os benefícios da aprendizagem e buscando provocar sentimentos de confiança, representam uma forma de contribuir para qualificar o processo de aprendizagem, em diferentes níveis de ensino.

Outro exemplo desse sentimento foi o relatado na entrevista de E5:

Quando a professora ... falou que faríamos um curso de metacognição, logo pensei que era algo chato, que não iria gostar, porque não sabia do que se tratava e o nome é difícil e aí parece ser complicado. Pensei, eu gosto de Física, vim para fazer Física e aí agora vou ter de estudar essas coisas que não sei bem para que serve. Só que gostei muito e achei que todos deveriam fazer o curso. Na verdade, consegui entender e achei a metacognição importante [...] agora estou motivado para estudar ela e usar [...] puxa como eu nunca me dei conta disso.

Esses exemplos de que os alunos apresentam inicialmente uma apatia em relação a um determinado assunto, mas que no contato deles com o tema, a situação se mostra favorável a uma mudança de sentimento, é outro fator importante em termos metacognitivos. A motivação como mostrou Zepeda et al. (2015) representa as crenças, objetivos e disposição dos alunos para aprender, o que leva a que se sintam predispostos a ativar formas de pensamento como os de natureza metacognitiva. Efklides (2006) mostra que a motivação é uma componente das experiências metacognitivas e, portanto, são determinantes para desencadear as interações com as estruturas de pensamento e que apoiam a evocação dos conhecimentos e habilidades metacognitivas.

A psicologia cognitiva, especialmente os estudos de David P. Ausubel vinculado a aprendizagem significativa, tem enfatizado que ela depende de um conjunto de elementos dentro os quais o de que o conhecimento precisa representar algo relevante e estar acompanhado de materiais que apresentam uma lógico/coerência interna, sendo potencialmente significativos para os estudantes. Além disso, o autor chama a atenção para o fato de que os estudantes precisam apresentar uma pré-disposição em aprender, o que remete de imediato ao sentimento de estar motivado. Ambas as condições mencionadas parecem ter se relevado no curso ministrado, uma vez que foi enfatizado na 
fala dos estudantes, a aquisição de conhecimentos sobre 0 assunto (metacognição), o acompanhamento em relação às atividades desenvolvidas nos encontros e o sentimento de estar motivado para aplicar o estudado.

\subsection{Potencialidade da metacognição e da proposta para a aprendizagem}

Outra categoria decorrente da fala dos entrevistados foi a potencialidade da metacognição para a aprendizagem em Física. Já no primeiro encontro essa questão veio à tona e revelou que os licenciandos perceberam a potencialidade no uso desse recurso de pensamento e passaram a buscar alternativas de avaliar sua utilização.

Entretanto, a de se considerar que os estudantes já estavam habituados a resolver problemas utilizando outras estratégias e que foi preciso um processo de desconstrução, de adaptação de seus recursos empregados ao longo dos anos e que até então vinham dando conta de responder as demandas de aprendizagem. A busca foi por mostrar a esses estudantes alternativas que poderiam ser utilizadas em situações que seus recursos se mostrassem limitados e também oportunizar que aprendessem algo que poderia beneficiar a aprendizagem de seus futuros alunos. Situação que foi mencionada por três dos entrevistados:

Acho bem importante e legal isso, mas na verdade resolvo de outro modo e ai fico um pouco perdido em como e quando utilizar.(E3)

Eu tinha que ter aprendido isso no colégio, talvez agora fosse mais fácil, porque quando vejo estou pensando para resolver do mesmo modo de antes.(E7)

Essas estratégias parecem ser fáceis e boas, mas eu preciso me concentrar pra usar elas, porque já estou acostumado a resolver tudo direto.(E8)

Apesar dessas manifestações de comparação em relação à forma tradicional como resolviam e a estratégia apresentada, os alunos revelaram perceber a sua validade e a potencialidades das estratégias metacognitivas. A fala de E10 evidencia isso:

Na minha opinião eu vejo que a metacognição é importante porque ajuda a pensar sobre o que estamos fazendo e no caso dos problemas de Física, que dados temos e que possibilidades temos de resolver. Ela parece forçar que a gente fique atento o tempo todo e não desvie a atenção, faz a gente ver o que sabe, discutir com o colega [...] essa discussão é um ponto muito importante, porque ela faz que a gente perceba se sabe ou não [...]. o planejamento e a avaliação final também são importantes. No final nunca havia me dado conta de que tenho de voltar e pensar se o resultado é coerente. 
A potencialidade no uso dos recursos metacognitivos na aprendizagem tem sido amplamente evidenciada nas pesquisas envolvendo os processos educacionais. No campo da resolução de problemas, Taasoobshirazi e Farley (2013) revelam que os recursos metacognitivos são os utilizados pelos aqueles que se mostram com mais expertise nesse tipo de ação e, portanto, deveriam ser considerados pelos professores como algo a ser incluído em sua ação pedagógica. Para os autores, a potencialidade de recorrer ao pensamento metacognitivo durante a resolução de problemas em Física está na oportunidade de realizar uma reflexão conceitual sobre os conhecimentos que cada estudante possui e o modo como deverá por em marcha para resolver o problema. Ryan et al. (2016), por sua vez, destacam que os benefícios da metacognição está na capacidade de autorregulação, envolvendo o planejamento, acompanhamento e a avaliação que são oportunizadas no decorrer da atividade. Esse movimento cognitivo propicia a vigilância necessária para pensar e refletir a ação, o que oportuniza ao êxito na atividade.

Analisando a falando de E1 percebe-se que ele mesmo sem ter conhecimento sobre metacognição, recorre a esse pensamento e, por isso, talvez, sua manifestação tenha sido de que "eu já faço isso, não verifico nada de novo que eu não faça, a não ser essa de ter de explicar para meu colega e preencher esse questionário". Essa fala corrobora o anunciado por Taasoobshirazi e Farley (2013) de que alunos com expertise utilizam estratégias metacognitivas mesmo sem ter consciência disso. Muito provavelmente seja o caso desse estudante que deve apresentar essa expertise na resolução de problemas em Física.

Sobre a diferença entre os iniciantes (novatos) e os que apresentam expertise em resolver problemas, destaca-se que, segundo Zajchowski e Martin (1993), os primeiros apresentam as mesmas condições que os segundos, apenas não o põem em movimento e se forem instigados a isso, por certo lograrão êxito na atividade de forma muito semelhante aos experts. Nesse caso, o importante seria identificar quais os que precisam de mais atenção e quais os que já executam esses procedimentos e permitir que eles interajam entre si. Situação de aprendizagem indicada por Ghiggi (2017) com umas possibilidades de resolução de problemas favorecida pela metacognição.

Outro aspecto analisado nesta categoria foi a utilização da proposta pelos entrevistados em suas aprendizagens no curso de Física. Considerando que a entrevista foi realizada um período após a realização dos estudos sobre metacognição, os alunos puderam avaliar a sua utilização nas disciplinas específicas do curso. Sobre isso é possível dizer que dos dez entrevistados, sete revelaram ter se beneficiado em seu processo de aprendizagem e, portanto, ter recorrido ao abordado no curso. 0 entrevistado E5 revelou que escreveu os questionamentos estruturados por ele no curso em um cartão e 
quando está com dificuldades para resolver um problema recorre ao guia de perguntas (prompts) como forma de orientá-lo. Além disso, menciona que o fato de refletir antes e pensar possíveis caminhos para solucionar o problema apresentado têm sido uma estratégia interessante e que tem ajudado em sua aprendizagem.

\subsection{Contribuições da proposta para o ensino}

Como terceira categoria discute-se as contribuições da proposta para o ensino de Física. Conforme mencionado na introdução do texto, os estudantes envolvidos neste estudo integram o Pibid que oportuniza, por meio de atividades nas escolas, o contato desses futuros professores com estudantes da educação básica. Nesse sentido, pode-se dizer que os sujeitos do estudo puderam avaliar a proposta apresentada em termos de sua utilização como estratégia de ensino.

Para tanto, durante a entrevista foi Ihes solicitado que "pensassem como professores". É bem sabido que isso é difícil para os estudantes, uma vez que sua experiência nessa área é pequena e, além disso, considera-se que pensar como professor envolve crenças e conhecimentos que vão além da proposta trabalhada. Contudo, julga-se que os estudantes entrevistados puderam fornecer ideias sobre a forma como a proposta poderia ser operacionalizada no contexto da educação básica e as possíveis potencialidades e limitações associadas a ela. As falas revelaram uma variedade de fatores e algumas divergências em termos dessa operacionalização no contexto escolar.

O mencionado por E3 é um exemplo de que os futuros professores conseguiram se posicionar como professores, mas que a experiência pedagógica ainda se encontra em um plano mais teórico e pouco embebido das especificidades decorrentes da vivência escolar. "eu adotaria essa estratégia desde o primeiro dia e assim faria os alunos pensar desta forma [...] acredito que ela ajudaria e eles poderiam aprender muito melhor." O mesmo se passa com o mencionado por E4: "Porque os professores não fazem isso? Eu como professor faria, não vejo dificuldades, levaria eles a pensar e usar esse tipo de estratégia".

Tais manifestações apontam para uma situação em que eles julgam ser uma decisão do professor a adoção de um ou outro tipo de estratégia e que os alunos passam a utilizar de forma incondicional. Rosa (2001) alerta que nem sempre as intencionalidades de um professor são recebidas e executadas por seus alunos, ou pelo menos não da forma como os professores 
gostariam que fosse. Segundo a autora há muitas variáveis em sala de aula e a opção por um método ou abordagem, tem efeitos diferentes dependendo do aluno. Dentre esses está a motivação e autodeterminação.

Muitos alunos estão na escola apenas para "passar por ali" sem uma preocupação imediata com a aprendizagem, tampouco estão interessados em desenvolver habilidades como as pertinentes a resolução de problema proposta. Seu desejo é achar uma resposta, não importa qual seja, mas ter a sensação de que executaram o solicitado e a partir de então estar livres; outros, no entanto, se sentem incapazes de executar qualquer ação, apresentando bloqueios em relação a aprendizagem e em particular, no campo das exatas, o que acaba por prejudicar a possibilidade de realizar tentativas. Tais características constituem o contingente da sala de aula, em que há uma diversidade de alunos e cujas abordagens metodológicas encontram diferentes ecos.

Dentre os entrevistados, alguns manifestaram esse entendimento e apontaram que a proposta poderia ser aceita e benéfica para uma grande parte dos alunos na educação básica, contudo, alertaram que haveriam os que não necessitariam ou mesmo não se mostrariam receptivos a essa proposta. Dentre esses entrevistados estão os E5, E6 e E9 cujos fragmentos de suas falas são reveladores desse entendimento.

Alguns alunos vão gostar e penso que até vai ajudar, mas outros provavelmente vão querer apenas achar a resposta e não ficar respondendo questionário ou discutindo com o colega. (E5)

Acredito que para os que têm dificuldade em aprender Física, a proposta vai ajuda, mas vai depender do aluno, porque muitos são desinteressados e vão reclamar de precisar pensar diferente. (E6)

Muitos têm dificuldades e acredito que eles vão aprovar esse modo de resolver problemas, mas sempre tem os que não vão gostar (E9)

Em termos da adoção dessa estratégia, os entrevistados mencionaram por unanimidade que adotariam e que o curso serviu como uma aprendizagem pedagógica, na qual oportunizou pensar no ser professor e em como planejar as aulas. Situação assim revelada por E2: "Vou tentar usar para ver se consigo melhorar minha aprendizagem e assim utilizar com meus alunos". O mesmo é mencionado por E7: "Quero utilizar isso quando eu for professor e se puder já no estágio. Penso que as estratégias metacognitivas podem ajudar muito os alunos, mas sei que vou precisar explicar bem e também utilizar elas durante as aulas". 
A fala de E7 remete a outra questão importante e explorada durante os encontros: a importância de que para utilizar em sala de aula como ferramenta pedagógica as estratégias metacognitivas, é necessário que o professor também as utilize, inclusive em seu planejamento de aula. Tal inferência é evidenciada por Monereo (2001) lembrando que se o professor deseja que seu aluno aprenda a utilizar esse tipo de estratégia é preciso, acima de tudo, que ele as utilize. Questão também inferida por Zohar e Barzilai (2013) ao se reportar a importância dos conhecimentos pedagógicos metacognitivos como conteúdos necessários para a formação de professores.

\section{CONSIDERAÇÕES FINAIS}

Como conclusão do presente estudo, menciona-se a importância da experiência vivenciada no âmbito do curso de formação de professores em Física desenvolvida a partir de um curso de extensão universitária, na qual os estudantes tiveram a oportunidade de aprender sobre metacognição e sua operacionalização no contexto da resolução de problemas. A atividade realizada em um curso de 20 horas, apesar de ser algo pequeno frente ao universo de uma carga horária de, no mínimo, 3200 horas de formação na graduação, representou um primeiro momento de contato com um corpo de conhecimentos pedagógico que poderá contribuir com sua ação profissional futura. Além disso, oportunizou benefícios para a aprendizagem dos conteúdos específicos durante o tempo em que estão realizando sua formação como professores de Física.

O objetivo do estudo realizado e divulgado como uma experiência vivenciada em um curso de formação inicial de professores, encontra-se atrelada a analisar a forma como esses futuros professores de Física concebem a metacognição como possibilidade de qualificação da sua aprendizagem na resolução de problemas. 0 intuito principal foi oportunizar o contato com essa perspectiva teórica e seus benefícios para a aprendizagem, evidenciando a necessidade de refletir e modificar as atitudes e crenças tradicionalmente presentes na ação didática, especialmente naquela focada em aspectos conteudistas e pouco voltados ao desenvolvimento da compreensão de como se aprende ou a reflexão sobre seus conhecimentos e a autorregulação.

Os resultados apontados pelas falas dos sujeitos da pesquisa evidenciaram que o conteúdo representava uma novidade, mas ao mesmo tempo possível de ser discutida nesta etapa de formação inicial; que os alunos se envolveram e se mostraram receptivos a essa abordagem estratégicas, tanto em termos da aplicação em sua aprendizagem nas disciplinas específicas do curso, como na sua operacionalização didática; que grande parte dos 
acadêmicos tem consciência de que as classes na educação básica são compostas por alunos que aprendem de forma diferente e que estratégias podem servir a alguns e que outros podem necessitar novos e diferentes elementos para estruturar sua aprendizagem; que a aprendizagem significativa está relacionada com um conjunto de elementos que envolve desde materiais potencialmente significativos até a disposição para aprender, aqui representada pela motivação; e, que para ensinar a recorrer a metacognição como estratégia de aprendizagem é preciso que eles professores também as utilizem no momento em que estão abordando os conteúdos disciplinares.

Por fim, menciona-se que a experiência apresentada neste texto refere-se a um caso específico, mas que fornece indícios da importância de oportunizar desde a formação inicial experiências didáticas e contemplar conteúdos pedagógicos como forma de que os futuros professores vivenciem tais experiências em suas aprendizagens, para somente a partir delas operacionalizá-las no contexto escolar.

\section{REFERENCIAIS}

Bardin, L.(2004). Análise de conteúdo. Lisboa: Edições 70.

Bogdan, R. C.e Biklen, S. K. (1994). Investigação qualitativa em educação: uma introdução à teoria e aos métodos. Porto: Porto Editora.

Brown, A. L. (1978). Knowing when, where, and how to remember: a problem of metacognition. In R. Glaser (Org.), Advances in instructional psychology (pp. 77-165). Hillsdale, New Jersey: Lawrence Erlbaum Associates.

Coleoni, E e Buteler, L. (2009). Students thinking during physics problem solving: identifying the resources with which they learn. Journal of Science Education, 10(1), 10-14.

Chi, M. T., Glaser, R. e Rees, E. (1982). Expertise in problem solving. In R. J. Sternberg (Org.). Advances in the psychology of human intelligence. v. 1 (pp. 7-75). Hilsdale, N.J.: Erlbaum.

Decreto $n^{\circ}$ 7.219, de 24 de junho de 2010. Dispõe sobre o Programa Institucional de Bolsa de Iniciação à Docência - Pibid e dá outras providências. Diário Oficial da União, n. 120 , seção $1,4-5$.

Duarte, R. (2004). Entrevistas em pesquisas qualitativas. Educar em Revista, 24, 213-225.

Flavell, J. H. (1976). Metacognitive aspects of problem solving. In L. B. Resnick (Ed.). The nature of intelligence (pp. 231-236). Hillsdale, NJ: LEA.

Efklides, A. (2006). Metacognition and affect: What can metacognitive experiences tell us about the learning process? Educational Research Review, 1(1), 3-14. 
Flavell, J. H. e Wellman, H. M. (1977). Metamemory. In R. V. Kail e J. W. Hagen (Eds.), Perspectives on the development of memory and cognition (pp. 3-33). Hillsdale, New Jersey: Lawrence Erlbaum Associates.

Gatti, B. (2014). A formação inicial de professores para a educação básica: as licenciaturas. Revista USP, São Paulo, 100, 33-46.

Georghiades, P. (2004). From the general to the situated: Three decades of metacognition. Research report. International Journal of Science Education, 26(3), 365-383.

Ghiggi, C. (2017). Estratégias metacognitivas na resolução de problemas em Física. (Dissertação de Mestrado em Ensino de Ciências e Matemática). Universidade de Passo Fundo, Passo Fundo, RS.

Hinojosa, J.y Sanmarti, N. (2016). Promoviendo la autorregulación en la resolución de problemas de Física. Ciência \& Educação, 22(1), 7-22.

Kistner, S., Rakoczy, K., Otto, B., Dignath-van Ewijk, C., Buttner, G. e Klieme, E. (2010). Promotion of self-regulated learning in classrooms: investigating frequency, quality, and consequences for student performance. Metacognition and Learning, 5(2), 157-171.

Lüdke, M. e André, M. E. D. A. (1986). Pesquisa em educação: abordagens qualitativas. São Paulo: EPU.

Malone, K. L. (2008). Correlations among knowledge structures, force concept inventory, and problem-solving behaviors. Physical Review Special Topics - Physics Education Research, 4(2), 020107-1 - 15.

Mello, G. N. (2000). Formação inicial de professores para a educação básica: uma (re)visão radical. São Paulo em Perspectiva, 14(1), 98-110.

Moser, S., Zumbach, J. eDeibl, I. (2017). The effect of metacognitive training and prompting on learning success in simulation based physics learning. Science Education, 101(6), 944-967.

Monereo, C. (2001). La enseñanza estratégica: enseñar para la autonomía. In C. Monereo (Org.). Ser estratégico y autónomo aprendiendo (pp. 11-27). Barcelona: Graó.

Reif, F. e Larkin, Jill H. (1991). Cognition in scientific and everyday domains: comparison and learning implications. Journal of Research in Science Teaching, 28(9), 733-760.

Rosa, C. T. W. (2001). Laboratório didático de Física da Universidade de Passo Fundo: concepções teórico-metodológicas. (Dissertação de Mestrado em Educação). Universidade de Passo Fundo, Passo Fundo, RS.

Rosa, C. T. W. (2011). A metacognição e as atividades experimentais no ensino de Física. (Tese de Doutorado em Educação Científica e Tecnológica). Universidade Federal de Santa Catarina, Florianópolis, SC.

Rosa, C. T. W. e Ghiggi, C. (2017). Monitoramento e controle metacognitivo na resolução de problemas em Física: análise de um estudo comparativo. Alexandria: Revista de Educação em Ciência e Tecnologia, 10(2), 105-125.

Ryan, Q. X., Frodermann, E., Heller, K., Hsu, L. e Mason, A. (2016). Computer problem-solving coaches for introductory physics: Design and usability studies. Physical Review Physics Education Research, 12(1), 0101051-17.

Taasoobshirazi, G. e Farley, J. A. (2013). Multivariate Model of Physics Problem Solving. Learning and Individual Differences, 24, 53-62. 
Thomas, G. P. (2013). Changing the metacognitive orientation of a classroom environment to stimulate metacognitive reflection regarding the nature of physics learning. International Journal of Science Education, 35(7), 1183-1207.

Ueno, M. H. (2004). A "tensão essencial" na formação de professores de Física: entre o pensamento convergente e o pensamento divergente. (Dissertação de Mestrado em Ensino de Ciências e Educação Matemática). Universidade Estadual de Londrina, Londrina, PR.

Zajchowski, R. e Martin, J. (1993). Differences in the problem solving of stronger and weaker novices in physics: Knowledge strategies, or knowledge structure. Journal of Research in Science Teaching, 30, 459-470.

Zepeda, C. D., Richey, J. E., Ronevich, P. e Nokes-Malach, T. J. (2015). Direct instruction of metacognition benefits adolescent science learning, transfer, and motivation: An in vivo study. Journal of Educational Psychology, 107(4), 954-970.

Zohar, A. e Barzilai, S. (2013). A review of research on metacognition in science education: current and future directions. Studies in Science Education, 49(2), 121-169. 
